\title{
Pengaruh Latihan Fisik Terhadap Penurunan Fatigue Pada Pasien Gagal Ginjal Kronik Yang Menjalani Hemodalisa Di RSUD Dr. H. Abdul Moeloek Provinsi Lampung
}

\section{Djunizar Djamaludin ${ }^{1}$, Eka Yudha Chrisanto² ${ }^{2}$ Mimin Septi Wahyuni ${ }^{3}$}

\author{
${ }^{1}$ Dosen Program Studi Keperawatan Universitas Malahayati \\ Email: bluenavi01@gmail.com \\ ${ }^{2}$ Dosen Program Studi Keperawatan Universitas Malahayati \\ Email:yudhachrisanto88@gmail.com \\ ${ }^{3}$ Mahasiswa Program Studi Keperawatan Universitas Malahayati \\ Email:miminsepti@gmail.com
}

\section{THE EFFECT OF PHYSICAL EXERCISE ON FATIGUE DECREASING IN CHRONIC CALCULATION FAILURE PATIENTS THAT HAVE HEMODALISA IN DR. H. ABDUL MOELOEKLAMPUNG PROVINCE}

Introduction: Based on the Bandar Lampung branch BPJS Health data, which covers several areas such as: Bandar Lampung, South Lampung (Lamsel), Pesawaran, Pringsewu, and Tanggamus, the number of dialysis medical measures in 2015 reached 52,721 cases (BPJS, 2015). As for the incidence of chronic kidney failure in Dr. H. Abdul Moeloek Lampung Province alone as many as 120 people, and 89 people underwent hemodialysis, in 2018, this data has increased compared to 2017, namely as many as 98 people who had CRF and underwent hemidialysis.

Objective: To analyze the effect of physical exercise on fatigue reduction in patients with chronic renal failure undergoing hemodalysis in Dr. Hospital $\mathrm{H}$. Abdul Moeloek Lampung Province.

Method: This type of research is quantitative. The design of the Quasi Experimental method with the One group pretest - posttest design approach. The population was 89 respondents, the sample used was 17 respondents, the sampling in the study was purposive sampling Statistical test using the dependent $t$-test.

Results: The average score of fatigue before being given physical training meant that fatigue scores were 34.41, which meant that respondents experienced fatigue, average fatigue scores after being given physical training, mean fatigue scores were 19.12, which meant respondents did not experience fatigue.

Conclusion: It means that there is an effect of physical exercise on fatigue reduction in patients with chronic kidney failure patients who undergo hemodalysis in Dr. Hospital. H. Abdul Moeloek Lampung Province, Suggestions for hospitals are expected to be able to make this physical exercise therapy an operational standard of nursing procedures in providing care as long as patients undergo hemodialysis.

Keywords $\quad$ : Physical Exercise, Fatigue, Hemodialysis

Djunizar Djamaludin ${ }^{1}$,Eka Yudha Chrisanto², Mimin Septi Wahyuni ${ }^{3}$

${ }^{1}$ Dosen Program Studi Keperawatan Universitas Malahayati. Email: bluenavi01@gmail.com

${ }^{2}$ Dosen Program Studi Keperawatan Universitas Malahayati. Email:yudhachrisanto88@gmail.com

${ }^{3}$ Mahasiswa Program Studi Keperawatan Universitas Malahayati. Email:miminsepti@gmail.com 
INTISARI: PENGARUH LATIHAN FISIK TERHADAP PENURUNAN FATIGUE PADA PASIEN GAGAL GINJAL KRONIK YANG MENJALANI HEMODALISA DI RSUD DR. H. ABDUL MOELOEK PROVINSI LAMPUNG

Pendahuluan: Berdasarkan data BPJS Kesehatan cabang Bandar Lampung, yang meliputi beberapa daerah seperti : Bandar Lampung, Lampung Selatan (Lamsel), Pesawaran, Pringsewu, dan Tanggamus, menunjukkan jumlah tindakan medis cuci darah pada 2015 mencapai 52.721 kasus (BPJS, 2015). Sedangkan untuk kejadian gagal ginjal kronik di RSUD Dr. H. Abdul Moeloek Provinsi Lampung sendiri sebanyak 120 orang, dan 89 orang menjalani hemodialisa, pada tahun 2018, data ini mengalami peningkatan jika dibandingkan pada tahun 2017 yaitu sebanyak 98 orang yang mengalami GGK dan menjalani hemidialisa (RSUD Dr. H. Abdul Moeloek, 2018)

Tujuan: Untuk menganalisa pengaruh latihan fisik terhadap penurunan fatigue pada pasien gagal ginjal kronik yang menjalani hemodalisa di RSUD Dr. H. Abdul Moeloek Provinsi Lampung Tahun 2019

Metode: Jenis penelitian ini adalah Kuantitatif. Desain penelitian metode Quasi Eksperimental dengan pendekatan One group pretest - posttest design. Populasi sebanyak 89 responden, sampel yang digunakan adalah 17 responden, pengambilan sampel pada penelitian adalah purposive sampling Uji statistik menggunakan uji t-tes dependen.

Hasil : Rata-rata skor fatigue sebelum diberikan latihan fisik mean skor fatigue sebesar 34,41 yang artinya responden mengalami kelelahan, rata-rata skor fatigue sesudah diberikan latihan fisik mean skor fatigue sebesar 19,12 yang artinya responden tidak mengalami kelelahan. Nilai $p$-value $0.000<0,05$.

Kesimpulan : Artinya terdapat pengaruh latihan fisik terhadap penurunan fatigue pada pasien gagal ginjal kronik yang menjalani hemodalisa di RSUD Dr. H. Abdul Moeloek Provinsi Lampung Tahun 2019, Saran bagi Rumah sakit diharapkan dapat menjadikan terapi latihan fisik ini sebagai standar operasional prosedur keperawatan dalam memberikan asuhan selama pasien menjalani hemodialysis.

Kata Kunci : Latihan Fisik, Fatigue, Hemodialisa

\section{PENDAHULUAN}

Insiden GGK diperkirakan sekitar 40-60 kasus per juta penduduk per tahun di negara-negara berkembang. Pravelensi dan insiden Chronic Kidney Disease terus meningkat di dunia tak terkecuali di Indonesia. Menurut Prof. Rully MA. Roesli, MD, PhD, FINASIM seorang ahli penyakit RS. Cipto Mangunkusumo dan anggota PB PERNEFI (Persekutuan Besar Perhimpunan Nefrologi Indonesia) "kemungkinan jumlah pasien gagal ginjal meningkat dari
19.612 hingga 100 ribu (2014 sampai 2019). Meningkatnya populasi tersebut dikarenakan minimnya kesadaran masyarakat untuk menjalani gaya hidup sehat. Imbasnya penyakit Chronic Kidney Disease pun mudah menjangkiti siapapun (PERNFERI, 2012; Nugroho, 2015).

Berdasarkan data dari PERFENI jumlah penyakit gagal ginjal kini di Indonesia cukup tinggi, dengan prevalensi penyakit gagal ginjal kronik mencapai 30,7 juta penduduk

Djunizar Djamaludin ${ }^{1}$,Eka Yudha Chrisanto ${ }^{2}$, Mimin Septi Wahyuni ${ }^{3}$

${ }^{1}$ Dosen Program Studi Keperawatan Universitas Malahayati. Email: bluenavi01@gmail.com

${ }^{2}$ Dosen Program Studi Keperawatan Universitas Malahayati. Email:yudhachrisanto88@gmail.com

${ }^{3}$ Mahasiswa Program Studi Keperawatan Universitas Malahayati. Email:miminsepti@gmail.com 
(PERNEFRI, 2012). Data PT Asuransi Kesehatan (ASKES), ada sekitar 14,3 juta orang penderita gagal ginjal kronik yang saat ini menjalani pengobatan yaitu dengan prevalensi 433 perjumlah penduduk, Jumlah ini akan meningkat hingga melebihi 200 juta pada tahun 2025 (Aini, 2015). Sedangkan pada tahun 2015 pravenlensi kejadian gagal ginjal kronis dengan melihat jumlah pasien baru sebanyak 21.050 orang, sedangkan pasien aktif sebanyak 39.554 orang, dan meningkat pesat pada tahun 2016 pasien baru sebanyak 25.446 orang, sedangkan pasien aktif sebanyak 52.835 orang (Kemenkes RI, 2018).

Berdasarkan data BPJS Kesehatan cabang Bandar Lampung, yang meliputi beberapa daerah seperti : Bandar Lampung, Lampung Selatan (Lamsel), Pesawaran, Pringsewu, dan Tanggamus, menunjukkan jumlah tindakan medis cuci darah pada 2015 mencapai 52.721 kasus (BPJS, 2015). Sedangkan untuk kejadian gagal ginjal kronik di RSUD Dr. H. Abdul Moeloek Provinsi Lampung sendiri sebanyak 120 orang, dan 89 orang menjalani hemodialisa, pada tahun 2018, data ini mengalami peningkatan jika dibandingkan pada tahun 2017 yaitu sebanyak 98 orang yang mengalami GGK dan menjalani hemidialisa (RSUD Dr. $\mathrm{H}$. Abdul Moeloek, 2018).

Hasil penelitian sebelumnya menunjukkan bahwa fatigue merupakan salah satu gejala yang paling umum dirasakan oleh pasien yang menjalani hemodialysis. Prevalensi kejadian fatigue antara $60 \%$ sampai $97 \%$ proses hemodialisis yang membutuhkan waktu selama 5 jam umumnya akan menimbulkan stres fisik pada pasien setelah hemodialisis (Danismaya, 2008;
Sakitri, 2018). Pasien akan merasakan kelelahan, sakit kepala dan keluar keringat dingin akibat tekanan darah menurun sehubungan dengan efek hemodialisis. Adanya status nutrisi yang buruk juga dapat menyebabkan penderita mengeluh malaise dan fatigue (Firmansyah, 2010; Sakitri, 2018). Fatigue merupakan keluhan utama pasien yang menjalani hemodialisis jangka panjang. Intervensi potensial yang dapat dilakukan untuk menurunkan fatigue meliputi energi konservasi, najemen aktivitas (latihan fisik), meningkatkan kualitas tidur, relaksasi otot, masase dan edukasi (Mitchell, et al, 2007; (Aini 2015).

Latihan fisik didefinisikan sebagai pergerakan terencana, terstruktur yang dilakukan untuk memperbaiki atau memelihara satu atau lebih aspek yang bertujuan untuk melatih kebugaran fisik (Orti, 2010; Sulistyaningsih, 2014). Secara umum tiga metode latihan yang dapat dilakukan pada pasien dengan penyakit ginjal tahap akhir yaitu program latihan di pusat rehabilitasi dengan supervisi, program rehabilitasi latihan di rumah dan program latihan selama satu jam pertama pada saat dilakukan hemodialisis di unit hemodialysis. Latihan fisik yang dilakukan selama dialisis dapat meningkatkan aliran darah pada otot dan memperbesar jumlah kapiler serta memperbesar luas permukaan kapiler sehingga meningkatkan perpindahan urea dan toksin dari jaringan ke vaskuler kemudian dialirkan ke dializer atau mesin hemodialisis (Sulistyaningsih, 2014).

Berdasarkan pemaparan diatas maka peneliti tertarik melakukan penelitian dengan judul "pengaruh latihan fisik terhadap penurunan fatigue pada pasien gagal ginjal 
kronik yang menjalani hemodalisa di RSUD Dr. H. Abdul Moeloek Provinsi

\section{METODE PENELITIAN}

Jenis penelitian ini merupakan jenis penelitian kuantitatif. Jenis penelitian kuantitatif adalah penelitian dengan memperoleh data yang berbentuk angka atau kualitatif yang diangkakan (Notoadmodjo, 2018). Rancangan dalam penelitian ini menggunakan desain Quasi Eksperimental dengan pendekatan one group pretest - posttest design. Populasi dalam penelitian penderita
Lampung Tahun 2019”

gagal ginjal kronik yang menjalani hemodilisa di RSUD Dr. H. Abdul Moeloek Provinsi Lampung sebanyak 89 orang pada tahun 2018. Berdasarkan perhitungan total sampel, maka jumlah responden adalah 15 responden, perhitungan tersebut ditambahkan dengan 10\%, sehingga diperoleh sampel sebanyak 17 responden. Pengolahan data menggunakan aplikasi SPSS versi 20.

\section{HASIL PENELITIAN}

Karakteristik Responden

Tabel 1.

Distribusi Frekuensi Usia Dan Lama Hemodialisa Pada Pasien Gagal Ginjal Kronik Yang Menjalani Hemodalisa Di RSUD Dr. H. Abdul Moeloek Provinsi Lampung Tahun 2019

\begin{tabular}{ccc} 
& $\mathbf{n = 1 7}$ & \\
\hline Usia & Frekuensi & Presentase (\%) \\
\hline 30 Tahun & 3 & 17,6 \\
$>30$ Tahun & 14 & 82,4 \\
\hline Lama Hemodialisa & Frekuensi & Presentase (\%) \\
\hline 1 Tahun & 2 & 11,76 \\
$>1$ Tahun & 15 & 88,24 \\
\hline
\end{tabular}

Berdasarkan tabel 4.1 diatas dapat dilihat jika usia responden terbanyak adalah usia lebih 30 tahun sebanyak 14 responden, dan lama hemodialisa lebih dari 1 tahun sebanyak 15 responden $(88,2 \%)$.

\section{Analisa Univariat}

Tabel 2.

Rata-Rata Penurunan Fatigue Sebelum Dan Sesudah Diberi Latihan Fisik Pada Pasien Gagal Ginjal Kronik Yang Menjalani Hemodalisa Di RSUD Dr. H. Abdul Moeloek Provinsi Lampung Tahun 2019

\begin{tabular}{cllll}
\hline Fatigue & $\mathbf{N}$ & Mean & SD & Min-Max \\
\hline Pretest & 17 & 34,41 & 5,386 & $28-45$ \\
\hline Postest & 17 & 19,12 & 3,080 & $13-23$ \\
\hline
\end{tabular}

Djunizar Djamaludin ${ }^{1}$,Eka Yudha Chrisanto ${ }^{2}$, Mimin Septi Wahyuni ${ }^{3}$

${ }^{1}$ Dosen Program Studi Keperawatan Universitas Malahayati. Email: bluenavi01@gmail.com

${ }^{2}$ Dosen Program Studi Keperawatan Universitas Malahayati. Email:yudhachrisanto88@gmail.com

${ }^{3}$ Mahasiswa Program Studi Keperawatan Universitas Malahayati. Email:miminsepti@gmail.com 
Dari tabel diatas dapat diketahui bahwa rata-rata skor fatigue sebelum diberikan latihan fisik di Ruang Hemodialisa RSUD Dr. H. Abdul Moeloek Provinsi Lampung Tahun 2019 terhadap 17 responden, dengan mean skor fatigue pada responden sebesar 34,41 yang artinya responden mengalamai kelelahan dengan standar deviasi 5,386 standar eror 1,306 dan nilai skor fatigue terendah sebesar 28 dan nilai nilai skor fatigue tertinggi sebesar 45 .
Dan dapat diketahui bahwa ratarata skor fatigue sesudah diberikan latihan fisik di Ruang Hemodialisa RSUD Dr. H. Abdul Moeloek Provinsi Lampung Tahun 2019 terhadap 17 responden, dengan mean skor fatigue pada responden sebesar 19,12 yang artinya responden tidak mengalami kelelahan, dengan standar deviasi 3,080 standar eror 0,747 dan nilai skor fatigue terendah sebesar 13 dan nilai nilai skor fatigue tertinggi sebesar

\section{Analisis Bivariat}

Tabel 3.

Pengaruh Latihan Fisik Terhadap Penurunan Fatigue Pada Pasien Gagal Ginjal Kronik Yang Menjalani Hemodalisa Di RSUD Dr. H. Abdul Moeloek Provinsi Lampung Tahun 2019

$$
\mathrm{n}=17
$$

\begin{tabular}{rccrlr}
\hline Variabel & Mean & SD & $T$ & P-Value & $95 \% \mathrm{Cl}$ \\
\cline { 1 - 2 } Pretest & 34,41 & 5,386 & \multirow{2}{*}{12,004} & 0.000 & $12,593-$ \\
\cline { 1 - 2 } Postest & 19,12 & 3,080 & & 17,995 & \\
\hline
\end{tabular}

Dari tabel diatas terlihat bahwa perbedaan hasil ratarata skor fatigue sebelum diberikan latihan fisik di Ruang Hemodialisa RSUD Dr. H. Abdul Moeloek Provinsi Lampung Tahun 2019 terhadap 17 responden, dengan mean skor fatigue pada responden sebesar 34,41 yang artinya responden mengalamai kelelahan standar deviasi 5,386 standar eror 1,306 dan nilai skor fatigue terendah sebesar 28 dan nilai nilai skor fatigue tertinggi sebesar 45, sedangkan sesudah diberi latihan fisik dengan mean skor fatigue pada responden sebesar 19,12 yang artinya responden tidak mengalami kelelahan standar deviasi 3,080 standar eror 0,747 dan nilai skor fatigue terendah sebesar 13 dan nilai nilai skor fatigue tertinggi sebesar 23.

Hasil uji statistik menggunakan tes-dependen didapat nilai $p$-value 0.000 terdapat pengaruh latihan fisik terhadap penurunan fatigue pada pasien gagal ginjalkronik yang menjalani hemodalisa di RSUD Dr. H. Abdul Moeloek Provinsi Lampung Tahun 2019.

Djunizar Djamaludin ${ }^{1}$,Eka Yudha Chrisanto ${ }^{2}$, Mimin Septi Wahyuni ${ }^{3}$

${ }^{1}$ Dosen Program Studi Keperawatan Universitas Malahayati. Email: bluenavi01@gmail.com

${ }^{2}$ Dosen Program Studi Keperawatan Universitas Malahayati. Email:yudhachrisanto88@gmail.com

${ }^{3}$ Mahasiswa Program Studi Keperawatan Universitas Malahayati. Email:miminsepti@gmail.com 
Pembahasan

Analisis Univariat

1. Rata-Rata Penurunan Fatigue Sebelum Diberi Latihan Fisik Pada Pasien Gagal Ginjal Kronik Yang Menjalani Hemodalisa Di RSUD Dr. $\mathrm{H}$. Abdul Moeloek Provinsi Lampung Tahun 2019

Rata-rata skor fatigue sebelum diberikan latihan fisik di Ruang Hemodialisa RSUD Dr. $\mathrm{H}$. Abdul Moeloek Provinsi Lampung Tahun 2019 terhadap 17 responden, dengan mean skor fatigue pada responden sebesar 34,41 yang artinya responden mengalami kelelahan standar deviasi 5,386 standar eror 1,306 dan nilai skor fatigue terendah sebesar 28 dan nilai nilai skor fatigue tertinggi sebesar 45 . Skor FAS 10-20 artinya tidak ada kelelahan (normal), dan dikatakan kelelahan yaitu skor 22-34, sedangkan kelelahan ekstrim yaitu skor lebih dari 35.

Fatigue dipengaruhi oleh beberapa faktor yang bervariasi, diantaranya kekurangan nutrisi, fisiologis yang tidak normal, dan kurang tidur (Astroth, Russell, \& Welch, 2013; Sakitri, 2018). Orang dewasa yang menerima hemodialisis khususnya yang mengalami fatigue meskipun pada posisi terlentang maupun duduk menunjukkan energi yang lemah, perubahan cairan dan kadar kimia darah (Jung \& Park, 2011; Sakitri, 2018)

Akibatnya pasien akan mengalami lelah, letih, lesu yang merupakan gejala fatigue. selain kelelahan dan kelemahan, komplikasi yang terjadi saat berlangsungnya hemodialisis yaitu Dialysis Disequilibrium
Syndrome (DDS). Dialysis Disequilibrium Syndrome dapat terjadi proses pengeluaran cairan dan urea dari dalam darah yang terlalu cepat selama hemodialisis. Tanda DDS berupa sakit kepala tiba-tiba, penglihatan kabur, pusing, mual, muntah, jantung berdebardebar, disorientasi dan kejang. Apabila DDS tidak terdeteksi klien dapat menjadi koma yang berakhir kematian (Maheswari, et al, 2012; Sakitri, 2018)

Menurut peneliti penyebab fatigue adalah lamanya menjalani hemodialisa, semakin lama seseorang menjalani hemodialisa maka akan semakin banyak efek samping yang ditimbulkan, seperti lelah, anemia. Fatigue dipengaruhi oleh beberapa faktor yang bervariasi, diantaranya kekurangan nutrisi, fisiologis yang tidak normal, dan kurang tidur. Orang dewasa yang menerima hemodialisis khususnya yang mengalami fatigue meskipun pada posisi terlentang maupun duduk menunjukkan energi yang lemah, perubahan cairan dan kadar kimia darah.

2. Rata-Rata Penurunan

Fatigue Sesudah Diberi Latihan Fisikpada Pasien Gagal Ginjal Kronik Yang Menjalani Hemodalisa Di RSUD Dr. H. Abdul Moeloek Provinsi Lampung Tahun 2019

Rata-rata skor fatigue sesudah diberikan latihan fisik di Ruang Hemodialisa RSUD Dr. $\mathrm{H}$. Abdul Moeloek Provinsi Lampung Tahun 2019 terhadap 17

Djunizar Djamaludin ${ }^{1}$,Eka Yudha Chrisanto², Mimin Septi Wahyuni ${ }^{3}$

${ }^{1}$ Dosen Program Studi Keperawatan Universitas Malahayati. Email: bluenavi01@gmail.com

${ }^{2}$ Dosen Program Studi Keperawatan Universitas Malahayati. Email:yudhachrisanto88@gmail.com

${ }^{3}$ Mahasiswa Program Studi Keperawatan Universitas Malahayati. Email:miminsepti@gmail.com 
responden, dengan mean skor fatigue pada responden sebesar 19,12 yang artinya responden tidak mengalami kelelahan standar deviasi 3,080 standar eror 0,747 dan nilai skor fatigue terendah sebesar 13 dan nilai nilai skor fatigue tertinggi sebesar 23.

Penelitian ini sesuai dengan teori gagal ginjal kronik yaitu kondisi dimana terjadi kerusakan ginjal dan penurunan kemampuan fungsi ginjal secara normal. Ginjal yang rusak terjadi peningkatan sisa metabolisme tubuh seperti ureum kreatinin. Gagal ginjal kronik juga menimbulkan komplikasi yaitu peningkatan tekanan darah, masalah tulang, kurangnya pemenuhan nutrisi dan kerusakan saraf, penyakit jantung dan pembuluh darah (National kidney foundation, 2017).

Latihan kekuatan merupakan salah satu jenis latihan fisik yang dibutuhkan pasien hemodialisis regular (Silva, et al., 2013; Widianti, Hermayanti, Kurniawan, 2017). Latihan kekuatan membuat otot lebih kuat dan bekerja lebih keras dengan melawan gaya resistensi. Keku atan otot dibutuhkan dan merupakan dasar untuk melakukan kemampuan fisik yang lain. Penelitian streghthening exercise dapat meningkatkan kekuatan otot pernapasan, kapasitas fungsional, dan kualitas hidup pada pasien hemodialisis (de Lima, et al, 2013).

Pada penelitian ini didapatkan hasil bahwa. Pada penelitian ini, saat dilakukan pengukuran setelah diberi intervensi dengan nilai rata-rata skor fatigue dengan nilai minimal 13 dan maksimal 23. Menurut peneliti hemodialisis adalah salah satu terapi ginjal yang menggunakan alat khusus dengan tujuan mengeluarkan toksin uremik (metabolic) dan mengatur cairan akibat penurunan laju filtrasi glomerulus dan mengambil alih fungsi ginjal yang menurun menggunakan membrane dialiser dengan teknik dialisis atau filtrasi, dapat dilakukan pada kondisi akut atau kronik.

\section{Analisa Bivariat}

1. Pengaruh Latihan Fisik Terhadap Penurunan Fatigue Pada Pasien Gagal Ginjal Kronik Yang Menjalani Hemodalisa Di RSUD Dr. H. Abdul Moeloek Provinsi Lampung Tahun 2019

Rata-rata skor fatigue sebelum diberikan latihan fisik di Ruang Hemodialisa RSUD Dr. $\mathrm{H}$. Abdul Moeloek Provinsi Lampung Tahun 2019 terhadap 17 responden, dengan mean skor fatigue pada responden sebesar 34,41 standar deviasi 5,386 standar eror 1,306 dan nilai skor fatigue terendah sebesar 28 dan nilai nilai skor fatigue tertinggi sebesar 45, sedangkan sesudah diberi latihan fisik dengan mean skor fatigue pada responden sebesar 19,12 standar deviasi 3,080 standar eror 0,747 dan nilai skor fatigue terendah sebesar 13 dan nilai nilai skor fatigue tertinggi sebesar 23 .

Hasil uji statistik menggunakan tes-dependen didapat nilai $p$-value 0.000 terdapat pengaruh latihan fisik 
terhadap penurunan fatigue pada pasien gagal ginjalkronik yang menjalani hemodalisa di RSUD Dr. H. Abdul Moeloek Provinsi Lampung Tahun 2019.

Sejalan dengan penelitian Efektivitas Latihan Fisik Selama Hemodialisis Terhadap Peningkatan Kekuatan Otot Pasien Penyakit Ginjalkronik Di Rumah Sakit Umum Daerah Kota Semarang. Perbedaan kekuatan otot kaki sesudah dilakukan latihan fisik pada kelompok perlakuan dan kelompok kontrol diuji dengan uji $t$ independent, sedangkan perbedaan kekuatan otot tangan setelah dilakukan latihan pada kelompok perlakuan dan kelompok kontrol diuji dengan Man-Withney. Hasil uji $t$ independent menunjukkan ada perbedaan kekuatan otot kaki setelah dilakukan latihan fisik pada kelompok perlakuan dan kelompok kontrol (nilai $\mathrm{p}=$ 0,027). Hasil uji Man Withney menunjukkan ada perbedaan kekuatan tangan setelah dilakukan latihan fisik pada kelompok perlakuan dan kelompok kontrol (nilai $\mathrm{p}=$ 0,030) (Sulistyaningsih (2014). Latihan fisik dilakukan pada saat pasien menjalani hemodialisis. Latihan dapat dilakukan selama 30 sampai dengan 45 menit dan secara umum diberikan sebelum hemodialisis selesai dilakukan (Cheema et al, 2006; Parsons, 2006; Hidayati 2009; Sulistyaningsih, 2014). Latihan dilakukan 2 set, 8 pengulangan untuk kelompok otot besar ekstremitas atas dan bawah untuk meningkatkan kekuatan otot.

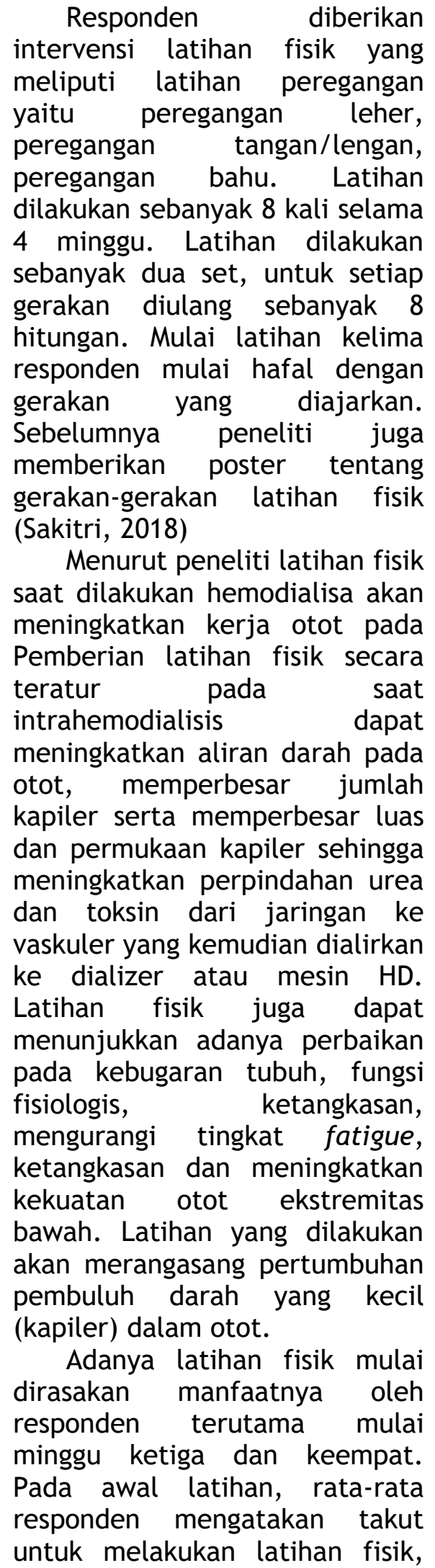

Djunizar Djamaludin ${ }^{1}$,Eka Yudha Chrisanto ${ }^{2}$, Mimin Septi Wahyuni ${ }^{3}$

${ }^{1}$ Dosen Program Studi Keperawatan Universitas Malahayati. Email: bluenavi01@gmail.com

${ }^{2}$ Dosen Program Studi Keperawatan Universitas Malahayati. Email:yudhachrisanto88@gmail.com

${ }^{3}$ Mahasiswa Program Studi Keperawatan Universitas Malahayati. Email:miminsepti@gmail.com 
karena takut mengganggu proses hemodialisis. Akan tetapi mulai minggu kedua dan seterusnya responden sudah tidak merasakan takut lagi. Salah satu responden mengatakan, setelah mengikuti latihan fisik ini badannya terasa lebih bugar, lebih enak. Selain itu terdapat juga responden yang mengatakan setelah mengikuti latihan ini, waktu dilakukan proses hemodialisa tidak langsung tidur, sehingga malam harinya merasa tidur lebih nyenyak dan bangun dalam kondisi segar.

\section{KESIMPULAN}

Diketahui karakteristik responden berdasarkan usia responden terbanyak adalah usia kurang dari 30 tahun yaitu 3 responden $(17,6 \%)$ dan usia lebih dari 30 tahun yaitu 14 responden $(82,4 \%)$, dan lama hemodialisa kurang dari 1 tahun yaitu $2(11,76 \%)$ dan lebih dari 1 tahun yaitu 15 responden $(88,24 \%)$. Rata-rata skor fatigue sebelum diberikan latihan fisik mean skor fatigue sebesar 34,41 yang artinya responden mengalami kelelahan. Rata-rata skor fatigue sesudah diberikan latihan fisik mean skor fatigue sebesar 19,12 yang artinya responden tidak mengalami kelelahan. Adanya pengaruh latihan fisik terhadap penurunan fatigue pada pasien gagal ginjal kronik yang menjalani hemodalisa di RSUD Dr. $\mathrm{H}$. Abdul Moeloek Provinsi Lampung Tahun 2019.

\section{SARAN}

Rumah sakit diharapkan dapat menjadikan latihan fisik ini dengan melakukan pergerakan dari kepala hingga kaki untuk mengurangi fatigue pada pasien yang mengalami gagal ginjal kronik sebagai standar operasional prosedur keperawatan dalam memberikan asuhan selama pasien menjalani hemodialysis dengan memberikan leaflet atau sop latihan fisik.

\section{DAFTAR PUSTAKA}

Aini, D. N. (2015). Pengaruh Latihan Fisik Terhadap Fatigue Pada Pasien Intrahemodialisis di RSUD Tugurejo Semarang.

Arikunto. (2013). Prosedur Penelitian Suatu Pendekatan Praktik. Jakarta: Rineka Cipta.

Caruso, J. F., Barbosa, A., Erickson, L., Edwards, R., Perry, R., Learmonth, L., \& Potter, W. T. (2015). Intermittent palm cooling's impact on resistive exercise performance. International journal of sports medicine, 94(10), 814-821.

Firmansyah, A. (2010). Usaha memperlambat perburukan penyakit ginjal kronik ke penyakit ginjal stadium akhir. Jakarta: PPDS Penyakit Dalam Fakultas Kedokteran Universitas Indonesia.

Fritz, S. (2012). Sports \& Exercise Massage-E-Book: Comprehensive Care for Athletics, Fitness, \& Rehabilitation. Elsevier Health Sciences.

Jung, T. D., \& Park, S. H. (2011). Intradialytic exercise programs for hemodialysis patients. Chonnam medical journal, 47(2), 61-65.

Kementerian Kesehatan Republik Indonesia (2018). Hasil utama riskesdas 2018. Jakarta: Kemenkes RI. 
Knap, B., Buturović-Ponikvar, J., Ponikvar, R., \& Bren, A. F. (2005). Regular exercise as a part of treatment for patients with endstage renal disease. Therapeutic Apheresis and Dialysis, 9(3), 211213.

Maheshwari, V., Samavedham, L., Rangaiah, G. P., Loy, Y., Ling, L. H., Sethi, S., \& Leong, T. L. W. (2012). Comparison of toxin removal outcomes in online hemodiafiltration and intradialytic exercise in high-flux hemodialysis: a prospective randomized open-label clinical study protocol. BMC nephrology, 13(1), 156.

Mitchell, S. A., Beck, S. L., Hood, L. E., Moore, K., \& Tanner, E. R. (2007). Putting evidence into practice: evidence-based interventions for fatigue during and following cancer and its treatment. Clinical journal of oncology nursing, 11(1).

Notoatmodjo. (2018). Metodologi Penelitian Kesehatan. Jakarta: Penerbit PT. Rineka Cipta.

Nugroho, S. H. P. (2015). Hubungan frekuensi konsumsi suplemen energi dengan stadium chronic kidney disease di ruang hemodialisis RSUD Ibnu Sina Gresik. Jurnal Surya, 7(01).

Parsons, T. L., Toffelmire, E. B., \& King-VanVlack, C. E. (2006). Exercise training during hemodialysis improves dialysis efficacy and physical performance. Archives of physical medicine and rehabilitation, 87(5), 680-687.
Pernefri (Perkumpulan Nefrologi Indonesia). 2012. Chronic Kidney Dieases. Jakarta : CV. Aksara Buana.

Sakitri, G. (2018). Pengaruh intradialytic exercise terhadap fatigue, kadar hemoglobin dan tekanan darah pasien hemodialisa di RSUP Dr. Soeradji Tirtonegoro Klaten (Doctoral dissertation, MKEP UMY).

Segura-Ortí, E. (2010). Exercise in hemodyalisis patients: a literature systematic review. Nefrología (English Edition), 30(2), 236-246.

Silva, S. F. D., Pereira, A. A., Silva, W. A. H. D., Simôes, R., Neto, B., \& de Resende, J. (2013). Physical therapy during hemodialyse in patients with chronic kidney disease. Brazilian Journal of Nephrology, 35(3), 170-176.

Sulistyaningsih, D. R. (2014). Efektivitas latihan fisik selama hemodialisis terhadap peningkatan kekuatan otot pasien penyakit ginjal kronik Di Rumah Sakit Umum Daerah Kota Semarang. In Prosiding Seminar Nasional \& Internasional (Vol. 2, No. 1).

Widianti, A. T., Hermayanti, Y., \& Kurniawan, T. (2017). Pengaruh Latihan Kekuatan terhadap Restless Legs Syndrome Pasien Hemodialisis. Jurnal Keperawatan Padjadjaran, 5(1).

Djunizar Djamaludin ${ }^{1}$,Eka Yudha Chrisanto ${ }^{2}$, Mimin Septi Wahyuni ${ }^{3}$

${ }^{1}$ Dosen Program Studi Keperawatan Universitas Malahayati. Email: bluenavi01@gmail.com

${ }^{2}$ Dosen Program Studi Keperawatan Universitas Malahayati. Email:yudhachrisanto88@gmail.com

${ }^{3}$ Mahasiswa Program Studi Keperawatan Universitas Malahayati. Email:miminsepti@gmail.com 